\title{
A LA CUMBRE POR UN VALLE. ADOLPHE DESOIGNIE, UN INGENIERO DE MINAS PIONERO EN LA ASTURIAS PROTOINDUSTRIAL
}

TO THE SUMMIT BY A VALLEY.ADOLPHE DESOIGNIE, A PIONEER MINING ENGINEER IN PROTO-INDUSTRIAL ASTURIAS

Jorge Muñiz Sánchez*

Universidad de Oviedo. España

\begin{abstract}
RESUMEN: Los años centrales del siglo XIX son uno de los vacíos más llamativos de la historiografía sobre la industrialización asturiana, puesto que constituyen el punto de despegue del proceso. En estas páginas se glosan las aportaciones técnicas de uno de los primeros ingenieros de minas que trabajaron en la región, el belga Adolphe Desoignie, que contribuyó a la transferencia de tecnología avanzada entre Europa y Asturias en esta fase liminar y decisiva. En 2019 se cumplieron 180 años de la puesta en marcha de la primera mina submarina documentada en el continente. Pese a ello, como otros coetáneos, no ha tenido la repercusión que merece en la literatura científica.
\end{abstract}

PALABRAS CLAVE: industrialización, minería del carbón, transferencia de tecnología, Bélgica, Real Compañía Asturiana de Minas.

ABSTRACT: The central years of the 19th century are one of the most striking gaps in historiography on Asturian industrialization, since they constitute the point of departure for the process. In these pages we focus on the technical contributions of one of the mining engineers who worked in the region, the Belgian, Adolphe Desoignie, who contributed to the transfer of advanced technology between Europe and Asturias in this initial and decisive phase. For example, 180 years ago, he launched the first submarine mine documented in Europe. Despite this, like other contemporaries, it has not had the repercussion it deserves in the scientific literature.

KEYWORDS: industrialization, coal mining, technology transfer, Belgium, Asturian Real de Minas.

\footnotetext{
* Correspondencia a: Jorge Muñiz Sánchez. Universidad de Oviedo, Departamento de Historia, Campus de Humanidades «El Milán», calle Teniente Alfonso Martínez, s/n, 33011 Oviedo, Asturias (Spain) - munizjorge@uniovi.es - https:// orcid.org/0000-0003-2224-0171
}

Cómo citar: Muñiz Sánchez, Jorge (2020). «A la cumbre por un valle. Adolphe Desoignie, un ingeniero de minas pionero en la Asturias protoindustrial»; Historia Contemporánea, 64, 749-773. (https://doi.org/10.1387/hc.20727).

Recibido: 1 abril, 2019; aceptado: 29 julio, 2019.

ISSN 1130-2402 - eISSN 2340-0277 / (C) 2020 UPV/EHU

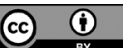

Esta obra está bajo una licencia

Creative Commons Atribución 4.0 Internacional 
Un hombre endeble que pretenda seguir la carrera de ingeniería para ejercer en ella su actividad, no será el más a propósito, pues tendrá que ir a veces a lugares desiertos; debe saber montar a caballo; muchas veces tendrá que acampar en despoblado, al pie de los montes o en el fondo de las barrancas; tiene que subir cerros, atravesar llanos, a veces a pie, a veces en cabalgadura, cargado en algunas ocasiones; debe ser hombre que resista la fatiga, que no le hagan mella las inclemencias del tiempo, que resista del mismo modo los rigores del sol de los trópicos que los hielos de los lugares más fríos. ${ }^{1}$

En la industrialización asturiana hay un período - grosso modo el segundo cuarto del siglo XIX - que ha quedado bastante al margen de los relatos historiográficos más usuales ${ }^{2}$. Las causas son probablemente complejas. En primer lugar hay que señalar la inaccesibilidad de la documentación, ya que hasta hace no muchos años el archivo hoy en día insoslayable para esta época - el de Asturiana de Zinc - ni siquiera existía y desde entonces se encuentra en un proceso de catalogación extremadamente concienzuda que afortunadamente hoy resulta muy fructuosa ${ }^{3}$. Por otro lado, el carácter un tanto enclavado y excéntrico geográficamente del foco principal en este momento con respecto al grueso de las zonas industriales de la provincia - de las cuales permanece relativamente aisladoprobablemente ha contribuido a su olvido a pesar de que su desarrollo es previo y mucho más firme. Tampoco la propia historia empresarial de la protagonista de estos años, la Real Compañía Asturiana de Minas (RCAM en lo sucesivo), que con razón ha sido calificada como «la primera empresa carbonera digna de tal nombre» ${ }^{4}$, ha sido una buena influencia a estos efectos. El muy apreciable desarrollo que siguió a su reconversión a la fundición de zinc en 1855 ha ensombrecido injustamente las dos primeras décadas de su existencia. En ellas, la RCAM - reducida a mina de carbón por el fracaso del proyecto metalúrgico previo- se limitó a tratar de so-

1 Aragón, 1906, p. 72.

2 De entre la bibliografía para el período posterior al aquí tratado se pueden mencionar, sin afán de exhaustividad y desde enfoques muy variados dentro de la historia social, Sierra Álvarez, 1990, Shubert, 1984, Álvarez Fernández, 2006 o Muñiz Sánchez, 2007. Sin embargo, la etapa previa no aparece más que como preludio en algunas obras de historia económica, como por ejemplo la por otra parte muy recomendable de García López, Peribáñez y Daroca, 2004.

${ }^{3}$ Es imposible transmitir una idea fiel de la inmensa labor de Alfonso García al frente de este archivo, que preserva y cultiva desde los heroicos tiempos iniciales hasta hoy.

${ }^{4}$ Nadal, 1975, p. 129. 
brevivir en un contexto difícil. Sin embargo, promovió la profesionalización y el desarrollo técnico de las explotaciones mineras, hasta entonces artesanales, de una forma notabilísima ${ }^{5}$.

Estos años iniciales han sido glosados por lo general desde el punto de vista de la historia económica y empresarial y como un preludio - por el que a menudo se pasa de puntillas - del éxito que vendría después, lo que a su vez explicaría la escasez de estudios relativos a esta fase liminar sobre la que llamó la atención el profesor José Sierra en 1991 sin que desde entonces haya sido paliada esta carencia ${ }^{6}$. Pese a ello, resulta evidente que la impronta de esta iniciativa empresarial es crucial, hasta el punto de ser la causante de la introducción y adaptación de términos de origen belga en el lenguaje no sólo del oficio sino también - trascendiendo la jergaen el acervo lingüístico común en Asturias ${ }^{7}$. Por fortuna, recientemente ha sido puesto de relieve el primer lustro, en el que otro ingeniero belga, Armand Nagelmackers, capitaneó un proceso de establecimiento y puesta en explotación del yacimiento en unas circunstancias cuando menos difíciles y peculiares. El carácter innovador de la empresa y la ausencia de consumidores industriales en el entorno inmediato, sumado a la falta de medios de transporte eficientes y económicos así lo determinaron ${ }^{8}$. Esta situación, lejos de mejorar, fue una de las causas de la dimisión de Nagelmackers y la llegada de Desoignie, que al tomar el relevo a finales de 1838 experimentó dificultades prácticamente idénticas a su predecesor.

Se pretende aquí profundizar en la incipiente tendencia a la recuperación de este período, a través de las aportaciones de Desoignie a la Asturiana de Minas y a la industria hullera de la provincia en general. Para ello, se parte de la hipótesis de que el ingeniero belga actuó como un agente bisagra («linking agent» en la terminología acuñada por Aitor Anduaga o «exchange engineer» en la de L.D. Ferreiro) que permitió la transferencia de tecnología entre su país de origen y Asturias ${ }^{9}$. Para tal propósito es imprescindible tratar de dibujar con la mayor precisión su actividad concreta en el desarrollo de los trabajos de la mina. La repercu-

5 Ezquerra, 1831. Todavía en 1860 la mitad de la producción hullera de la provincia se debía a estas explotaciones primitivas, llamadas «de paisanos». Coll Martín y Sudriá i Triay, 1987, p. 63.

6 García López, Peribáñez y Daroca, 2004, p. 9. Sierra Álvarez, 1991, p. 3.

7 Sierra Álvarez, 1991, p. 6.

8 Muñiz Sánchez, 2019,pp. 42-67.

9 Anduaga, 2001, Ferreiro, 2006. 
sión de los agentes como Desoignie en la transferencia de tecnología ha sido señalada por algunos como un factor más relevante que la importación de máquinas y literatura técnica, dado que la transferencia siempre precisa de un acomodo a las circunstancias locales que únicamente puede aportar un técnico in situ y que, además implica un «conocimiento tácito» que incluye habilidades y aprendizaje y que difícilmente se puede escribir o analizar ${ }^{10}$. Con este fin se tratará de glosar la figura de Desoignie de la forma más integral posible, con especial atención a sus aportaciones en diferentes aspectos de la producción y distribución de la hulla, así como a su actividad al margen de la empresa que le llevó a Asturias, ámbito en el que también ejerció un importante papel innovador.

\section{Del núcleo a la periferia de la industrialización europea}

¿Por qué un ingeniero que se encuentra en el epicentro mismo de la industrialización continental europea acepta un trabajo en un lugar desconocido, en un recóndito paraje de un país atrasado en el que todo está por hacer? Podríamos pensar que para un principiante - como lo era Desoignie en 1838, puesto que había terminado sus estudios en 1837- constituía una buena oportunidad de adquirir experiencia en el oficio. Sin embargo, cuando se considera que era sobrino de François Isidore Dupont - senador y uno de los industriales más destacados de Bélgica, que pretendía darle empleo en sus establecimientos - la duda reaparece de forma más que razonable. ¿Fue el espíritu de aventura que sin duda animó a muchos como él en la época? ¿O fue la vinculación a Adolphe Lesoinne, hijo de uno de los socios fundadores y profesor suyo en una de las primeras promociones de la Escuela de Minas de Lieja? Con Lesoinne y los fundadores españoles de la RCAM compartía además el credo liberal, que le llevó a colaborar con El Eco de Avilés, primer periódico de esta villa y órgano del progresismo ${ }^{11}$. Esta ligazón, así como en general las redes profesionales que este tipo de instituciones educativas generaban $-\mathrm{y}$ siguen generando en alguna medida - parece una explicación plausible aunque necesariamente insuficiente. En cualquier caso, no debe menospreciarse, y menos tratándose de alguien de tanto peso en el mundo académico e in-

10 Anduaga, 2001, pp. 46, 65.

11 De la Madrid, 2008, pp. 18-22. García López, Peribáñez y Daroca, 2004, p. 12. 
dustrial belga como Lesoinne, que, en palabras del propio Desoignie, le «dispensaba inmerecido aprecio» ${ }^{12}$. Con todo, no cabe desechar completamente la hipótesis del carácter fuerte y arrojado del personaje que nos ocupa como elemento importante en la toma de la decisión, como se deducirá fácilmente de la consideración de unos mínimos datos biográficos.

Adolphe Jean-Baptiste Charles Desoignie Silez, hijo de un comisario de policía, nació en el seno de una familia de cuatro hermanos en HaineSaint-Paul (La Louvière, distrito de Soignies) en 1816. En su breve autobiografía, escrita en español, dice que sus abuelos maternos eran aragoneses, pero precisa que llegaron a Bélgica «en tiempos de Carlos I ${ }^{13}$, por lo que parece evidente - por biología y cronología - que estamos ante una interferencia de su lengua materna, el francés, en la que el vocablo «aïeuls» significa efectivamente «abuelos», pero también «antepasados», de un modo más genérico. Como se ha señalado ya, estudió en la Escuela de Ingeniería de Minas de Lieja, fundada pocos años atrás precisamente por el mencionado Adolphe Lesoinne. Apenas titulado, éste le propuso sustituir al dimitido Nagelmackers - que significativamente también había sido alumno de Lesoinne - al frente de la mina de Arnao. En septiembre de 1838 ambos partieron de Amberes en un barco cargado con materiales y utillaje desconocidos o difíciles de encontrar en España con rumbo a Asturias. Así se ponía al mando de la que en aquella época fue la única mina de carbón con pretensiones de explotación racional y moderna en Asturias, porque el ambicioso proyecto de Alejandro Aguado, marqués de las Marismas - al frente del cual se puso precisamente Nagelmackers - abortó en sus inicios por la prematura muerte del promotor $^{14}$. Tuvo tiempo de realizar la carretera carbonera a través de la Compañía del Camino Carbonero entre Sama y Gijón, pero su Compagnie des Mines d'Espagne, llamada a beneficiar con medios modernos amplias concesiones mineras, no tuvo desarrollo y sus activos terminaron siendo adquiridos por el duque de Riánsares, personaje más inclinado a la espe-

12 Bulletin de l'Association des ingénieurs des mines sortis de l'Ecole de Liège, 4-51898 , p. 64. La información contenida en estos boletines se debe a la amable colaboración de Mr. Bruno Guidolin (CLADIC-Centre liègeois d'archives et de documentation de l'industrie charbonnière). DESOIGNIE, 2016. Mercedes de Soignie, tataranieta del ingeniero y escritora, hace un relato de la historia familiar en el que incorpora unos «Apuntes biográficos» de seis páginas manuscritas que su antepasado escribió en diciembre de 1884 . Sobre Dupont, véase Brigode, s/d.

13 De Soignie, 2016, pp. 19-22 y 25.

14 González Llanos, 1842. 
culación y los manejos político-económicos que a la inversión productiva, como es sabido ${ }^{15}$.

\section{Prometeo entre mortales. Un difusor de técnicas y tecnologías}

Recientemente se ha puesto de relieve el papel del primer ingeniero director de la RCAM en Arnao, Armand Nagelmackers, en la transferencia de tecnología de Europa a Asturias ${ }^{16}$. Resulta bastante natural que personas con la formación y los conocimientos de otras cuencas hulleras que atesoraban estos pioneros generaran un flujo de conocimientos, que vamos a continuación a tratar de detallar mínimamente para el caso de su sucesor, Desoignie. Más adelante nos detendremos en sus publicaciones, pero antes se hace obligado sondear su influencia directa y práctica, a pie de obra. Algunos la han situado con razón por delante de la importación de máquinas y textos científico-técnicos en su importancia para una transferencia que siempre precisa de una adaptación a las peculiaridades del destino que sólo puede aportar un ingeniero con conocimiento de la plaza $^{17}$.

\section{a) Transportar y almacenar}

Es sintomático que las primeras preocupaciones del nuevo director a su llegada a Arnao estuvieran más relacionadas con el transporte del carbón a los mercados que con su propia extracción. Algo tan aparentemente anodino como evacuar la producción - que además había motivado la elección de esta mina por su cercanía al mar, que supuestamente prodigaba facilidades - terminó convirtiéndose en un asunto crucial por las estrecheces del mercado nacional, la ausencia de consumidores de enjundia en las cercanías y la bravura del océano en esa costa, que dificultaba enormemente las operaciones desde los tiempos de Nagelmackers, en los que sólo se podía embarcar el carbón con cierta seguridad durante cuatro o cinco meses al año por las condiciones de la mar. Su sucesor continuaba dependiendo del embarcadero construido por él a pie de mina para poder

\footnotetext{
15 González Prieto, 2017, pp. 17-68.

16 Muñiz Sánchez, 2019, pp. 42-67.

17 Anduaga, 2001, p. 65.
} 
vender una hulla que por vía terrestre veía aumentar vertiginosamente sus costes camino del puerto de Avilés ${ }^{18}$.

Para tratar de aliviar en lo posible esta situación emprendió desde los instantes iniciales una estrategia de mejora de los elementos que estaba a su alcance remozar razonablemente. El primero de ellos era el mencionado embarcadero, eslabón inicial del periplo de la hulla de Arnao, fuera cual fuera su destino. Nagelmackers - siempre falto de recursos económicos por la escasa prodigalidad de los socios de la RCAM en esa época embrionaria - había establecido un plano inclinado sobre el que se vaciaban los carros y que permitía que el carbón cayera a las lanchas que se colocaban bajo él. Un modo económico de hacerlo, pero poco rentable porque la hulla se rompía mucho con tanto ajetreo y perdía valor, cuando no iba a parar directamente al mar, dado que las lanchas difícilmente estaban quietas en el sitio establecido por el fuerte oleaje. Desoignie mejoró este sistema disponiendo unos cubos de seis quintales de capacidad sobre carriles que podían frenarse al llegar abajo hasta liberar su carga en el momento estimado más conveniente, cuando la lancha estuviera bien ubicada ${ }^{19}$.

Otro detalle nada irrelevante era la condición de quienes transportaban las lanchadas desde Arnao hasta el puerto. Desoignie continuó experimentando otro problema heredado de la época anterior, ya que la Comandancia de Marina de Gijón le exigía que fueran marineros matriculados como tales. Esto dificultaba mucho el hallar tripulaciones porque reducía notablemente el universo y encarecía los jornales. Para librarse de este condicionante, el ingeniero escribió a las autoridades recordándoles que por Real Orden de 1 de mayo de 1836 - firmada por Mendizábal y de la que conservaba una copia - la reina había concedido a la RCAM libertad para transportar siempre que fuera en buques matriculados y con tripulantes nacionales, condiciones que cumplían exquisitamente pese a utilizar «terrestres» como mano de obra ${ }^{20}$.

El tercer gran pilar de la primera etapa del transporte era el almacenaje. Dado que durante meses no se podía hacer por mar el trayecto Arnao-Avilés, se imponía aprovechar la época favorable para constituir en la villa un remanente de carbón con el que atender mínimamente los compromisos de otoño e invierno. Sin embargo esto provocaba una pérdida

\footnotetext{
18 García López, Peribáñez y Daroca, 2004,p. 18.

19 González Lasala, 1991, p. 21. Un quintal equivale a 46,008 kg.

20 Carta de Desoignie a la Comandancia de Marina de Gijón, 3-2-1839, AHAZ, Caja 1234, legajo 35 .
} 
de calidad del carbón allí abandonado a la intemperie, por lo que iniciaría la construcción de un almacén para evitarlo ${ }^{21}$. La iniciativa pronto encontró acogida, porque otras minas de la zona - Ferroñes y Santo Firme, entonces dirigidas por Adrian Paillette - seguirían y profundizarían esta estela ${ }^{22}$. La propia RCAM había construido rápidamente un segundo almacén para asegurarse siempre la presencia de entre $10.000 \mathrm{y}$ 15.000 quintales en el embarcadero y evitar quejas y pérdidas por sobreestadías de los barcos ${ }^{23}$.

\section{b) Producir. A la cumbre por un valle}

Sin embargo, la base de todo y el motivo por el que Desoignie estaba en Arnao era producir carbón. Y su principal aportación al respecto fue establecer - en 1839, apenas llegado- labores por debajo de las poco rentables desarrolladas hasta entonces, que se encontraban además muy próximas a agotarse ${ }^{24}$. Lo hizo con «una galería maestra inclinada llamada del Valey (término minero belga) para el beneficio de la parte más profunda del banco ${ }^{25}$. La obra - también llamada en ocasiones vallée o vallée nouvelle - reunía complejidades técnicas indudables, ya que el terreno resultó ser pesado y en descomposición por la acción de las corrientes naturales de agua, necesitando obras de albañilería para evitar derrumbes en la entrada y a la vez preservar en el futuro una eventual máquina de extracción de la caída de piedras ${ }^{26}$. Es reseñable que el ingeniero tuviera ya en mente un método de extracción mecánico en una época tan temprana - cuando no eran muy frecuentes, como indica Luis Mansilla - ${ }^{27}$ a pesar de que en Arnao se optó entonces por un malacate de tracción animal. En cualquier caso, el rendimiento de la pareja de bueyes era altamente satisfactorio para el belga en 1841, cuando calculaba que permitían extraer diariamente entre 70 y 80 carros de 7 quintales ${ }^{28}$.

\footnotetext{
${ }^{21}$ Carta de Desoignie a N.-M. Lesoinne, 25-1-1839, AHAZ, Caja 1234, legajo 39.

22 Vilela Campo, 2008, p. 145.

${ }^{23}$ Carta de Desoignie a A. Lesoinne, 26-7-1839, AHAZ, LCC.

${ }^{24}$ Carta de Desoignie a Ferrer, 28-2-1843, AHAZ, LCC.

25 González Lasala, 1991, p. 15.

26 Carta de Desoignie a N.-M. Lesoinne, 25-1-1839, AHAZ, Caja 1234, legajo 39.

27 Mansilla Plaza, 2011, p. 101.

${ }^{28}$ Carta de Desoignie a A. Lesoinne, 19-4-1841, AHAZ, LCC.
} 
A la cumbre por un valle. Adolphe Desoignie, un ingeniero de minas pionero en la Asturias ...

A las dificultades inherentes a la construcción del valey se fueron sumando algunos imponderables, como la falta de una cadena o cable de extracción apropiado o la proximidad a galerías inundadas de una mina antigua y el riesgo de filtraciones que comportaba, que llevó a paralizar los avances a finales de 1839 hasta el término de la temporada lluviosa ${ }^{29}$. Pese a todo, la nueva explotación se encontraba plenamente productiva pocos meses después, aunque fue frecuente que encontrara fallas que interrumpían la extracción de carbón hasta que se podía hallar de nuevo la veta $^{30}$. Lo tortuoso de la geología, que es frecuente en Asturias, se verifica también en Arnao. Sin ir más lejos, a los pocos días de la interrupción de los avances de 1839 Desoignie informaba a A. Lesoinne de la existencia de una súbita caída casi vertical del filón, lo que dificultaba bastante las labores ${ }^{31}$. No es sorprendente, a la luz de estos y otros inconvenientes, que el ingeniero sintiera una gran responsabilidad y en el momento de llegar a adentrarse el valey bajo el mar solicitara la opinión experta de su maestro y jefe Adolphe Lesoinne: «j'ai besoin de vos conseils, de votre présence à Arnao, afin de dissiper mes doutes et arrêter un système d'exploitation dont la moindre faute pourrait [...] avoir des conséqueces les plus fâcheuses ${ }^{32}$.

El sistema establecido por Desoignie, cuidado en el mínimo detalle, lo conocemos gracias a Guillermo Schulz, que en el Boletín Oficial de Minas de 1844 hacía una descripción bastante minuciosa. Por aquel entonces discurría a 160 pies de profundidad, con inclinación de 18 a 34 grados y una longitud de 330 varas $^{33}$. Pero lo más llamativo eran los espesores del filón, que alcanzaban unos treinta pies muy sorprendentes y favorables para el contexto asturiano, para el que todavía en 1885 se calculaban espesores no superiores a 1,20 metros, es decir, unos cuatro pies y medio ${ }^{34}$. El valey contaba con un doble ferrocarril, con el acceso para obreros a un lado y las máquinas de desagüe al otro. El desagüe - siempre delicado pero especialmente en una mina tan cercana al mar- se

${ }^{29}$ Cartas de Desoignie a A. Lesoinne, 26-7-1839, y a Riera, 24-12-1839, AHAZ, LCC. Vilela Campo, 2008, p. 82.

${ }^{30}$ Carta de Desoignie a Adolphe Lesoinne, 31-7-1840, AHAZ, LCC. Vilela Campo, 2008, p. 111.

31 Carta de Desoignie a A. Lesoinne, 31-12-1839, AHAZ, LCC.

32 Carta de Desoignie a A. Lesoinne, 3-6-1842, AHAZ, LCC.

33 El pie castellano tiene una longitud de 0,278635 metros y la vara son tres pies, es decir, $0,835904 \mathrm{~m}$.

34 Muñiz Prada, 1885, pp. 19-20. 
realizaba por «bombas de mano impelentes de madera, ingeniosamente dispuestas» aunque pronto serían sustituidas por otras de hierro colado ${ }^{35}$. En las galerías de explotación estaba establecido un sistema por el que se avanzaba practicando un túnel estrecho y dejando mucho carbón a los lados que posteriormente se abatía en retirada y «con largas herramientas construidas a propósito», permitiendo el derrumbe del conjunto ${ }^{36}$. Esta práctica - heredada del primer ingeniero de la RCAM, Armand Nagelmackers - era debida a la mala mar existente en el lugar y las dificultades para transportar el carbón. Durante los meses más inclementes se practicaban las galerías y cuando las condiciones meteorológicas eran más favorables se procedía a provocar el derrumbe, obteniendo así la mayor parte de la producción de forma rápida en los momentos óptimos para su transporte ${ }^{37}$. De este modo se ahorraban también gastos de sostenimiento de las galerías, pero se corría un riesgo que no escapaba a Schulz, quien alababa la pericia de ingeniero y capataces por «no haber ocurrido hasta ahora desgracia alguna notable», pese a que se extraía sin rellenar e incluso a menudo sin entibar ${ }^{38}$. Para ello Desoignie se basó con seguridad en la experiencia previa de Nagelmackers, pero también en lo visto en su visita a la mina de Gouley, en Aquisgrán, dirigida por otro ingeniero liejense, Lambert Rasquinet ${ }^{39}$. Sin embargo, pasada la época de especial necesidad de los inicios, este sistema se sustituyó muy rápidamente por otro más selectivo que evitaba la mezcla de carbones de distintas calidades y por tanto optimizaba el rendimiento económico, arrancando primero el carbón de primera calidad de la parte inferior del banco y después la parte superior - de segunda clase - dejando intacto entre ellos un intermedio pizarroso, en un método muy semejante al que Ezquerra del Bayo llama de «macizos prolongados» y que, en este caso, permitía la extracción sin mezcla de calidades y por tanto con un notable beneficio ${ }^{40}$. Se utilizaban picos convencionales, dado que no podía

35 Carta de Desoignie a A. Lesoinne, 26-4-1839, AHAZ, LCC. Schulz, 1844, p. 142.

36 Schulz, 1844, p. 142.

37 Carta de A. Nagelmackers a Ferrer, 16-1-1838, AHAZ, LCC. Cartas de Desoignie a A. Lesoinne, 31-7-1840 y 31-12-1839, AHAZ, LCC.

${ }^{38}$ Carta de Desoignie a A. Lesoinne, 26-7-1839, AHAZ, LCC. Guillermo SCHULZ, «Concluye el informe sobre algunas minas de carbón de Asturias», Boletín Oficial de Minas, 1844, p. 142.

39 Cartas de Desoignie a A. Lesoinne, 18-10-1839 y 31-12-1839, AHAZ, LCC. Carta de Desoignie a A. Lesoinne, 17-3-1840, AHAZ, Caja 1234, legajo 40.

${ }^{40}$ González Lasala, 1991, p. 19. Ezquerra del Bayo, 1839. 
usarse el conocido como «regadera»-enteramente de hierro- por la dureza del carbón, que hacía igualmente necesario el empleo de barrenos. La pólvora se usó desde el principio por la RCAM y constituía una ventaja competitiva porque el carbón así extraído tenía un calibre - y por tanto un valor - mayor que el más menudo obtenido exclusivamente con picos, que era el que se podía encontrar en el mercado, procedente de las minas de Langreo ${ }^{41}$.

El valey supuso probablemente la salvación de la empresa en aquel momento, porque la mina explotada por Nagelmackers se agotó en 1839 y por lo tanto fue la única en beneficio desde entonces hasta el descubrimiento en 1842 de la conocida como del Arco y su posterior puesta en explotación ${ }^{42}$. Pese a ello resultaron unos años duros, en los que los trabajos fueron principalmente de establecimiento de las nuevas labores, complicadas por las fallas. Hubo, por tanto, poca producción y Desoignie tenía dificultades para explicarlo ante los requerimientos de sus jefes menos familiarizados con los aspectos técnicos ${ }^{43}$. A esto había que sumar inconvenientes en el aprovisionamiento de materiales básicos como el hierro, lo que lastraba enormemente las operaciones. Sin embargo, los resultados en el avance del valey, la buena calidad de su carbón - que Adrian Paillette clasificó entre las hullas secas de llama larga - y el progreso de la producción desde entonces desactivaron las intenciones de venta que había abrigado Adolphe Lesoinne en $1843^{44}$. En consecuencia, podemos afirmar que el valey resultó providencial. Concebido por nuestro ingeniero, fue ejecutado en muy buena medida por Malaise, uno de los capataces belgas que desde los inicios trabajaban en la mina y que habían ido formando a los nativos en una provincia donde no existían aún verdaderos mineros de oficio ${ }^{45}$. Su experiencia y conocimientos también le resultaron claves a Desoignie para llevar a cabo su proyecto, como hacía notar a sus jefes: «Cette vallée est le chef d'oeuvre de Malaise» ${ }^{46}$. En buena lógica, cuando le llegó la orden de enviar al citado durante tres meses a Bélgica no pudo evitar lamentarse: «je vous adresse Malaise, malgré le grand besoin que

${ }^{41}$ Carta de Armand Nagelmackers a Riera, 8-3-1836, AHAZ, LCC. González Lasala, 1991, p. 16.

42 Carta de Desoignie a G. Schulz, 21-10-1842, AHAZ, LCC.

43 Carta de Desoignie a Ferrer, 28-2-1843, AHAZ, LCC.

44 García López, Peribáñez y Daroca, 2004, pp. 28 y 31.

45 Vilela Campo, 2008, p. 29.

46 Carta de Desoignie a A. Lesoinne, 26-4-1839, AHAZ, LCC. 
j'en ai» ${ }^{47}$. Debe consignarse además que la consideración hacia él era unánime, ya que el Nagelmackers agobiado por falta de liquidez económica de mediados de 1838 pensaba ante todo en las consecuencias que la falta de pago pudiera tener para sus dos maestros mineros belgas más apreciados, Malaise y Nicolas: «que vont ils devenir?» ${ }^{48}$. Esto constituye un ejemplo de que la transferencia de técnicas no sólo tiene un elemento crucial en la práctica - probablemente más relevante que la vertiente teórica $-{ }^{49}$, sino que además no depende sólo de los ingenieros, sino también de técnicos intermedios como son los que aquí se mencionan.

La experiencia del agotamiento de la primera mina puesta en explotación por Nagelmackers, así como el abandono en su época de las de San Juan y Santa María por escaso rendimiento, son factores - sumados al interés exploratorio que cabe suponer a un ingeniero al frente de una concesión vastísima en superficie- que explican la frecuencia de las calicatas practicadas por el belga. En cualquier caso, éstas eran por lo general de resultado más incierto que las del valle del Nalón, donde los yacimientos forman casi un contínuo garantizando prácticamente los hallazgos ${ }^{50}$. El resultado más notable fue el descubrimiento de la mina del Arco, gracias a las indicaciones de Adolphe Lesoinne en una de sus visitas ${ }^{51}$. Este filón, al Sur del valey, vino a atenuar la dependencia de éste, aportando carbón de una gran calidad además. Para extraer sus hullas se establecieron un ferrocarril y un plano inclinado que «pone esta mina en comunicación con el embarcadero de Arnao» ${ }^{52}$.

\section{c) Otras aportaciones técnicas de Desoignie}

Como se ha mencionado, el sistema de transporte interior era el ferrocarril de tracción humana ${ }^{53}$ No fue Desoignie, sino su antecesor Nagelmackers, quien inició su construcción al poco de constituirse la empresa

47 Carta de Desoignie a A. Lesoinne, 18-5-1839, AHAZ, LCC.

48 Carta de Nagelmackers a N.-M. Lesoinne, 28-6-1838, AHAZ, Caja 1234, legajo 39.

49 Anduaga, 2001, p. 65.

50 González Lasala, 1991, p. 11.

51 Cartas de Desoignie a A. Lesoinne, 21-4-1840 y a Schulz, 21-10-1842, AHAZ, LCC.

52 González Lasala, 1991, p. 15.

53 Carta de Desoignie a A. Lesoinne, 19-4-1841, AHAZ, LCC. Schulz, 1844, p. 142. 
y pudo empezar a utilizarlo en 1837, por lo que hablamos del primero de España ${ }^{54}$. En cambio, sí introdujo las vagonetas metálicas, ya que hasta entonces habían sido de madera y empezaron a confeccionarse de hierro colado, por lo que aumentó su capacidad y también su resistencia ${ }^{55}$. Para ello recurrió a materiales importados de Bélgica, algo comprensible dadas las dificultades de aprovisionarse en España aunque tortuoso por los tiempos y los problemas aduaneros: ruedas, ejes, planchas metálicas, raíles y algunas arrobas de acero belga, que los herreros sintomáticamente preferían al nacional ${ }^{56}$. Esto también constituye una innovación relevante, puesto que lo normal en la época para el transporte interior en España eran los capazos, las carretillas y otros métodos semejantes. Incluso en otras latitudes el empleo de vagones sobre raíles metálicos no se consolida hasta mediados de siglo y en la Península Ibérica aún más tarde ${ }^{57}$.

Para la extracción al exterior se utilizaba - se ha indicado ya - un malacate tirado por una pareja de bueyes capaces de sacar en una jornada entre 500 y 600 quintales según los cálculos del ingeniero, que contaba con adquirir una segunda pareja si las necesidades de la producción se acentuaban. El coste diario de este sistema era de unos seis reales, mucho más barato que el torno manual que se utilizaba previamente y que parece ser lo más común en la época ${ }^{58}$. Para instalar este elemento Desoignie pidió - entre otros enseres - que le enviaran de Bélgica una cadena:

[...] une chaîne en fer battu pour notre vallée nouvelle. Toutes nos ressources en ce genre ont été épuissés par la prolongation de notre frein et de notre vallée intérieure. Notre vallée nouvelle ayant un fort pendage de $45 .^{\circ}$, il serait bien que la chaîne fut un peu plus forte que la dernière venue de Belgique..$^{59}$

Los detalles no eran irrelevantes en absoluto, como se puede deducir de las palabras del ingeniero. La pronunciada pendiente, la dureza del terreno, la longitud... aconsejaban utilizar materiales de la máxima

${ }^{54}$ Cartas de Armand Nagelmackers a Ferrer, 15-9-1835, y a A. Lesoinne, 22-2-1837, AHAZ, LCC. García López, Peribáñez y Daroca, 2004, pp. 9 y 25.

55 Schulz, 1844, p. 142. García López, Peribáñez y Daroca, 2004, p. 52.

56 Carta de Desoignie a N.-M. Lesoinne, 22-2-1839, AHAZ, LCC.

57 Mansilla Plaza, 2011, p. 101.

58 Carta de Desoignie a A. Lesoinne, 19-4-1841, AHAZ, LCC. Mansilla Plaza, 2011, p. 96.

${ }^{59}$ Carta de Desoignie a Nicolas-Maximilien Lesoinne, 22-2-1839, AHAZ, LCC. 
resistencia, puesto que todo indica que ya anteriormente habían experimentado dificultades al respecto. Las cadenas de eslabones coexistían en esta época con los cables de fibra vegetal - que no eran aptos para muchos usos - pero tenían también problemas porque sus roturas eran frecuentes y su peso muy grande ${ }^{60}$. Por eso es comprensible que pidiera una cadena de hierro pudelado, fabricada con el procedimiento que si bien en el Reino Unido tenía ya una trayectoria de unas décadas, en el continente europeo era una innovación del primer cuarto de siglo ${ }^{61}$. El desarrollo de los acontecimientos daría la razón - para su desgracia - a Desoignie al adoptar todas estas precauciones. Unos meses después, en mayo de 1840, participaba a Adolphe Lesoinne que se proponía introducir los cables de hierro trenzado para sustituir a los vegetales y las cadenas. Esto quiere decir que o bien no obtuvo los materiales que anhelaba el año anterior o no resultaron satisfactorios para la función que les reservaba, aunque es más probable lo primero $^{62}$. Para ello decía no necesitar más que el hilo de hierro apropiado, puesto que él los había visto fabricar en las minas de Aquisgrán, que - como ya se ha señalado al tratar el sistema de explotación - conoció en persona ${ }^{63}$. Los cables metálicos tenían capacidades de carga diez veces superiores a los vegetales y se fabricaban con alambres que se iban entrelazando sobre un núcleo de cáñamo embreado llamado alma, que les confería mayor flexibilidad. Se inventaron en 1834 y se usaron por primera vez en las minas de Clausthal, en Alemania ${ }^{64}$.

Pero la historia del cable de extracción iba a ser mucho más compleja y tortuosa, como se adelantaba. En enero de 1842 Desoignie confesaba a Adolphe Lesoinne que estaba a punto de romperse por segunda vez y que no sabía a qué achacar su acelerada usura, dado que había procurado que los ángulos en su recorrido fueran muy abiertos. Por ello le rogaba una orientación sobre cómo resolver el problema, puesto que preveía que proveerse de cable o de hilo inglés sería prácticamente imposible ${ }^{65}$. La siguiente noticia que tenemos se la debemos a Schulz, que nos indica que en 1844 Desoignie había vuelto a la cadena de eslabones de hierro, «de

\footnotetext{
${ }_{60}$ Mansilla Plaza, 2011, p. 97.

61 Barajas, 2003, p. 64.

${ }^{62}$ Carta de Desoignie a A. Lesoinne, 26-7-1839, AHAZ, LCC.

63 Carta de Desoignie a Adolphe Lesoinne, 22-5-1840, AHAZ, LCC.

64 Mansilla Plaza, 2011, p. 97.

65 Carta de Desoignie a A. Lesoinne, 2-1-1842, AHAZ, LCC.
} 
5 líneas de espesor» ${ }^{66}$. Así pues, el tratado es un episodio más de transferencia temprana de tecnología, si bien en este caso no llega a cuajar inicialmente. Entre las posibles causas podemos mencionar la dureza del terreno en el que operaba -extrema por momentos: «un grès presque inattaquable»- y lo temprano de su aplicación en Arnao, apenas cinco años después de su invención y cuando la técnica todavía no estaría madura $^{67}$.

Interesa destacar también que fueron varias las influencias de su compatriota Lambert Rasquinet - otro ingeniero belga expatriado al servicio de una empresa belga, en este caso en la futura Alemania - las que inspiraron a Desoignie en la RCAM. Su visita a Aquisgrán debió producirse probablemente durante sus estudios, puesto que al poco de finalizarlos se fue a trabajar a Arnao. En la mina de Gouley pudo aprender de Rasquinet no sólo aspectos de la explotación que se han señalado ya, sino también los detalles de la confección de estos cables formados por hilos de hierro. Conviene resaltar la importancia de los viajes de instrucción de los ingenieros de minas, que tiene sus orígenes en esta época en Europa ${ }^{68}$. Gracias a esto, Desoignie incluso tendría la fortuna de conocer el sistema de guías - que pronto se convertirían en raíles - para evitar oscilaciones en la extracción inventado por su anfitrión. Previamente a 1827 se sujetaban las vagonetas al cable sin más, resultando un viaje accidentado con múltiples derrames y percances ${ }^{69}$. Estamos por tanto de nuevo ante una técnica de muy reciente aparición y cuya difusión paulatina encontró, una vez más, un reflejo temprano en Asturias gracias a la presencia belga.

Sin embargo, no todo lo que aportó Desoignie a la incipiente minería asturiana fueron grandes innovaciones en el sistema de producción. Realizó también algunas adquisiciones de utillaje que, sin resultar centrales para la labor minera, constituyeron un avance indudable sobre lo preexistente y contribuyeron a ampliar los horizontes en la provincia. En esta categoría podemos destacar dos elementos: los gorros - provenientes de Lieja y antecesores del casco de seguridad muchas décadas antes de que se hiciera relativamente frecuente - y las lámparas ${ }^{70}$. Si sumarios

66 Schulz, 1844, p. 142.

67 Carta de Desoignie a A. Lesoinne, 31-12-1839, AHAZ, LCC. González Lasala,1991, p. 16.

68 Garçon, 2004, p. 237.

69 Pasleau, 1996, pp. 140-144.

70 García López, Peribáñez y Daroca, 2004, p.52. 
debían ser los primeros no menos resultarían las segundas: «unos candiles de chapa delgada de hierro construidos en Bélgica y en un todo semejantes a los que en Almadén usan los Ingenieros y Capataces, pero algo más pequeños que los de aquel establecimiento» ${ }^{71}$. En Asturias se las conoce como «sapos» por su forma y tenían unos dos siglos de historia en el momento en que empezaron a usarse en Arnao, lo que no empece que fueran un avance sobre los candiles artesanales previamente empleados y, sobre todo, que iniciaran un camino ${ }^{72}$. Eran de llama libre, sin ninguna protección, pero esto no suponía un problema en una mina en la que no se constataba la presencia de gases inflamables en cantidades relevantes. Se las alimentaba con aceite de linaza - más barato y abundante en Asturias que el de oliva - y como lo pagaba la empresa era el capataz el encargado de distribuirlo y controlar su consumo ${ }^{73}$.

\section{Ingeniero y empresario}

La influencia de Desoignie en los albores de la industrialización asturiana, a partir de lo señalado hasta aquí, parece evidente en su puesto de director de la mina de la RCAM. Ese período termina con su dimisión a mediados de 1855 , motivada por su fuerte carácter, el descontento con el papel que se le reservó en el nuevo organigrama y la incompatibilidad con su nuevo jefe, Jules Hauzeur, sobrino de Adolphe Lesoinne ${ }^{74}$. Sin embargo, su influjo sobre el desarrollo económico y social de su patria de adopción no se detiene en esta fecha. La salida de la RCAM, habida cuenta de sus cargas familiares - tuvo diez hijos - debió de suponer un serio hándicap desde el punto de vista personal ${ }^{75}$. Según sus memorias, a los pocos meses de salir de Arnao se fijó en el incipiente negocio carbonero y de mineral de hierro, fundamentalmente en el valle del Nalón, donde adquirió «varias pertenencias por compra y por vía de concesión pero equivocados para mi fueron dichos cálculos como lo fueron para muchos extranjeros llevados por el mismo pensamiento» ${ }^{76}$.

71 González Lasala, 1991, p. 24.

72 Llaneza Díaz y Trinidad, 2009, pp. 39-40.

73 González Lasala, 1991, p. 24.

74 Carta de Desoignie a Jonathan Raphaël Bischoffsheim, 22-6-1855, AHAZ, LCC.

75 De Soignie, 2016, p. 116.

76 Desoignie, 2016. 
En 1859 trabajó unos meses como ingeniero jefe en las minas del duque de Riánsares en Langreo, que abandonó muy rápidamente «por la imposibilidad de enderezar los abusos, el robo y la estafa que al parecer eran constante práctica en dicha administración sin que de nada sirvieran mis propósitos y conatos de reforma» ${ }^{77}$. No debe resultar sorprendente que un espíritu recto y directo chocara con la organización de la empresa de tan oportunista sujeto. Poco después se fue a Galicia a dirigir las minas de estaño de Domingo Merelles, un afamado liberal con el que tampoco debió terminar a bien ${ }^{78}$. Todas estas actividades las simultaneará con los trabajos para el Ayuntamiento de Avilés, del que será el primer ingeniero titulado y en el que llevará a cabo importantes obras en la década de los sesenta ${ }^{79}$.

A su vuelta de Galicia, tras haber vendido por mediación de su amigo Schulz parte de sus minas para obtener liquidez, se dedicó a la ingeniería civil y a dirigir sus explotaciones hasta 1877 o $1878^{80}$. En ellas encontró dificultades que no resultan en absoluto sorprendentes:

Los carbones menudos de Langreo tenían en aquel entonces muy escaso destino y se arrojaban [a] los terreros y faltaban vías de comunicación y sobraban a menudo fallas, estrechones, circunstancias que mermaban en gran manera el producto de la explotación para mi faltaba sobre todo capital y la astucia mercantil $[\ldots] .{ }^{81}$

Las dificultades de transporte ya experimentadas en Arnao, pero acrecentadas, los problemas relacionados con la geología de los yacimientos... Estos inconvenientes le llevaron a proponer en 1858 en las páginas de la Revista Minera que la administración pública velara para que se pusieran en común los datos acumulados por particulares sobre la estratigrafía del valle de Langreo, que resultaba estratégica para evitar sor-

77 Bulletin de l'Association des ingénieurs sortis de l'École de Mines de Liège, $\mathrm{n} .^{\mathrm{o}} 1$, janvier 1860, p. 30. Desoignie, 2016.

78 Porto, 1846, p. 33. Desoignie, 2016.

79 Libro de sesiones del Ayto. de Avilés 1860-1863, pp. 46-48, 119-120, 161, 164, 167-168, 228, 248-249, 263, 280, 300, 403-405, Archivo Histórico de Avilés. De Soignie, 2016, p. 113.

80 Bulletin de l'Association des ingénieurs sortirs de l'École de Mines de Liège, n. ${ }^{\circ} 5$, janvier 1861 , p. 213 , n. ${ }^{\circ} 9$, janvier 1862 , p. 387, n. ${ }^{\circ} 1-1868$, p. 7 , n. ${ }^{\circ} 1-1869$, p. 21 , n. ${ }^{\circ} 1-1870$, p. 22 , n. ${ }^{\circ} 1-1871$, p. 23 , n. ${ }^{\circ} 1-1877$, p. XXXIII, n. ${ }^{\circ} 1-1878$, p. XXXV.

81 Desoignie, 2016. 
presas a los empresarios inversores ${ }^{82}$. Pero probablemente lo peor fuera su falta de liquidez económica, que cabe suponer que fue lo que le llevó a establecer un sistema «de arriendo a la cuarta», por el que cedía la explotación a trabajadores, que debían entregarle un canon del 25\%. Esta fórmula permitía obviar la falta de capital y recuerda al destajo establecido en sus tiempos en la $\mathrm{RCAM}^{83}$. También era empleado por las primeras grandes empresas mineras para evitar tener que ocuparse directamente de dos difíciles aspectos: el reclutamiento y la vigilancia de los trabajadores, además de mantener pobladas minas que no estaban en condiciones de explotar de otro modo, evitando así que pudiera retirárseles la concesión por inactividad ${ }^{84}$. Pese a ello, su posición relativa entre los productores de hulla en la provincia fue paulatinamente descendiendo. Mientras en 1860 daba trabajo a unos 120 obreros diarios, en 1863 eran 77 y producía 106.250 quintales métricos, en 1865 ya sólo eran 44.400 quintales y ocupaba el noveno puesto entre los productores y en 1875 era el decimoséptimo con $41.096^{85}$. Tuvo más de veinte concesiones mineras y cuando se deshizo de ellas - a finales de los setenta - se ganó la vida con sus proyectos de ingeniería civil y con un breve intento de establecer una herrería en La Louvière, su tierra natal ${ }^{86}$. También hizo tentativas en los campos de la inmobiliaria y de la ostricultura en San Juan, prodigándole esta última bastantes pérdidas al parecer ${ }^{87}$.

${ }^{82}$ Desoignie, 1858, p. 472.

83 Estadística Minera, 1863, p. 34.

${ }^{84}$ González Prieto, 2017, pp. 254-258.

85 El quintal métrico contiene $100 \mathrm{kgs}$.

86 Estatutos y reglamento de la Sociedad Especial Minera Concordia de Mieres, Oviedo, Imp. de Benito González, 1860, p. 13. Estadística Minera, 1863, p. 34, 1865, p. 92,1870 , p. 68,1873 , p. 73 y 1875 , p. 67. El Constitucional, 10-3-1875, p. 4. El Imparcial, 15-3-1875, p. 2. Gaceta de los caminos de hierro, 18-4-1875, p. 13 y 25-4-1875, p. 13. Bulletin de l'Association des ingénieurs sortis de l'École de Mines de Liège, $\mathrm{n} .^{\circ}$ 1/2janv.-févr. 1880, p. XXXVII, n. ${ }^{\circ}$ 1/2-janv.-févr. 1881, p. XXXVIII, n. ${ }^{\circ}$ 1/2-janv.-févr. 1882 , p. XLV, n. ${ }^{\circ} 1 / 2$-janv.-févr. 1883, p. XLI, n. ${ }^{\circ} 1 / 2$-janv .-févr. 1884, p. XLI, n. ${ }^{\circ} 1 / 2-$ janv.-févr. 1885, p. XLI, n. ${ }^{\circ}$ 1/2-janv.-févr. 1886, p. XLI, n. ${ }^{\circ}$ 1/2-janv.-févr. 1887, p. XLII, n. ${ }^{\circ}$ 1/2-janv.-févr. 1888, p. XLII, n. ${ }^{\circ} 1 / 2$-janv.-avr. 1889, p. XLIII, n. ${ }^{\circ} 1$-janv.-févr. 1890 , p. XLIII, n. ${ }^{\circ} 1$-janv.-févr. 1891 , p. XLIII, n. ${ }^{\circ} 1$-janv.-févr. 1892 , p. XLIII, n. ${ }^{\circ} 1$-janv.-févr. 1893, p. XLIII, T. XIX, 1896, p. XLIII.

${ }^{87}$ De Soignie, 2016, pp. 112 y 119. 


\section{Conclusión}

Como se ha ido detallando, nos hallamos ante uno de los primeros ingenieros de minas titulados que ejercieron en Asturias, que trabajó en las primeras empresas hulleras dignas de tal nombre, prodigó innovaciones técnicas de los más variados tipos e impulsó el desarrollo del sector convirtiéndose en empresario con resultados parece que poco favorables para su bolsillo pero sin duda relevantes para el flujo de conocimientos de $\mathrm{Eu}-$ ropa a Asturias que ya había contribuido a establecer en sus tiempos en la RCAM. Todo lo anterior le convirtió en un personaje público en un momento en el que los peritos en aspectos técnicos escaseaban enormemente. Paradójicamente, uno de los factores de su éxito profesional fue la adopción de métodos poco o nada ortodoxos - alejados sin duda de lo prescrito en términos teóricos por la formación académica recibida-, como desarrollar labores sin entibar o permitir el derrumbe sistemático de galerías, entre otras prácticas aquí mencionadas. Esta flexibilidad da testimonio de la idea expresada en la introducción, según la cual la pericia de los técnicos superiores e intermedios es crucial en la adopción de innovaciones por transferencia de tecnología, que - al no operar sobre sustratos preexistentes homogéneos - siempre necesita adecuaciones iniciales e in media res. La capacidad de adaptación e improvisación permitió a Desoignie afrontar las limitaciones de capital, abastecimiento y mercado de venta que experimentó. Formó parte de los círculos sociales más avanzados y relevantes, como su participación en El Eco de Avilés atestigua ${ }^{88}$. En su ámbito profesional estuvo muy bien considerado y fue aceptado por sus iguales, grandes figuras también de la industrialización que él mismo nos recuerda: Manby, Paillete, Curé... y por supuesto Guillermo Schulz, quien fue su amigo hasta el final ${ }^{89}$. Pero también tuvo relación más o menos estrecha con Denis Thiry - quien le sustituiría al frente de la mina de Arnao- y Francisco Antonio Elorza, entre otros ${ }^{90}$. Tampoco le faltaron los contactos en ámbitos más académicos, como lo fue León Pérez de Salmeán, liberal como él, catedrático de Química aplicada interesado por las minas y futuro rector de la Universidad de Oviedo ${ }^{91}$.

88 De la Madrid, 2008, pp. 18-22.

${ }^{89}$ Desoignie, 2016. De Soignie, 2016, pp. 40 y 122. González-Pumariega y González Prieto, 2017, p. 237.

90 Vilela Campo, 2008, p. 175.

91 Carta de Schulz a Desoignie, 23-3-1841, AHAZ, LCC. 
El hecho de ser extranjeros casi todos estos ingenieros precursores - aunque algunos, como el propio Desoignie, enraizarían profundamente en el territorio con el tiempo- fue sin duda un factor aglutinante adicional, como también debieron serlo las múltiples dificultades que este período pionero opuso a sus desvelos. Es comprensible que las ocasiones para la sociabilidad se sucedieran, ya fuera de forma distendida en torno a una comida o por motivos más profesionales cuando hizo falta defender los aranceles al carbón británico frente a las acometidas del industrial metalúrgico andaluz Manuel Agustín de Heredia, interesado en poder comprar combustible británico barato pero no por ello partidario de una apertura análoga del mercado metalúrgico nacional ${ }^{92}$. Es más, con cierta frecuencia se establecieron entre ellos relaciones familiares, como de nuevo es el caso de Desoignie y Nagelmackers, dado que sus esposas eran primas entre sí ${ }^{93}$. Además Desoignie - a pesar de lo temprano de su llegada a Asturias - nunca perdió los lazos con el ambiente industrial de su país natal, donde mantuvo amigos tan relevantes como Louis Trasenster - destacado liberal, ingeniero y rector de la Universidad de Lieja - y formó parte de la asociación de antiguos alumnos de la Escuela de Minas de esta localidad, en la que asistió en 1872 a su vigesimoquinto aniversario aunque no pudo por su salud estar presente en el quincuagésimo, en 1897, unos meses antes de morir ${ }^{94}$. También tuvo un papel relevante en la ingeniería civil, sobre todo a través de sus trabajos para el Ayuntamiento de Avilés, aunque esto trasciende los objetivos de este artículo ${ }^{95}$.

El reconocimiento le llegó no sólo por la vía informal de la consideración prodigada por sus colegas y compañeros, sino también de otros modos más solemnes. Fue nombrado Caballero de la Real Orden de Carlos III, formó parte de la Sociedad Económica de Amigos del País -en la que recomendó a Schulz- e ingresó en 1851 en la Société Géologique

92 Cartas de Nagelmackers a Desoignie, 20-12-1843 y 28-4-1847, AHAZ, Caja 1234 , legajo 39. Carta de Desoignie a Ferrer, 2-5-1843, AHAZ, LCC. p. 59.

93 Carta de Desoignie a A. Lesoinne, 31-12-1839, AHAZ, LCC. De Soignie, 2016,

94 Bulletin de l'Association des ingénieurs des mines sortis de l'Ecole de Liège, 4-51896, p. 64. Carta de Desoignie a Adolphe Lesoinne, 18-10-1839, AHAZ, LCC. González-Pumariega y González Prieto, 2017, p. 237. Deferme and Maeyer, 2009, p. 151. De Smaele, 1999, p. 339.

95 De Soignie, 2016, pp. 111-115. 
de France, apadrinado por el alemán al mismo tiempo que Elorza ${ }^{96}$. En el terreno civil, fue nombrado cónsul de Bélgica en Avilés en 1853. Los datos sobre su renuncia posterior no son coincidentes porque algunas fuentes mencionan su dimisión cuatro años después por la poca disponibilidad que le dejaba su ajetreada vida profesional mientras otras lo sitúan todavía en ejercicio en $1879^{97}$. En cualquier caso, la permanencia en el cargo no es lo más relevante a nuestros efectos.

Una parte sustancial de su legado técnico - o al menos la más evidente - la constituyen sus obras escritas. Esta es una de las principales diferencias con su compatriota Nagelmackers, que no nos dejó ningún texto publicado conocido, lo que puede deberse al menor número de posibilidades de edición en su época, pero probablemente también a un desinterés por dejar ese tipo de huella. En cambio, en el caso de Desoignie parece existir una voluntad de trascender. A partir de 1850 empieza a publicar en revistas especializadas - que están comenzando su andadura - y en las que incluso forma parte del círculo promotor. Los detalles de la muy relevante explotación que dirige en Arnao, con el novedoso valey, le permiten hacerlo ${ }^{98}$. La gran obra de ingeniería civil que suponen el túnel y el ferrocarril costero que construye hasta el puerto en la época de creación de la fábrica de zinc y justo antes de su salida de la RCAM resulta también sugerente entre los técnicos e incluso en círculos más amplios, contribuyendo a esta relevancia social mencionada ${ }^{99}$. Desde su dimisión en la RCAM sus intereses se amplían y su pluma va dejando en un segundo plano las cuestiones puramente mineras para ocuparse de aspectos de ingeniería más diversos, entre los que tendrán siempre un lugar preferente sus dos grandes pasiones: el ferrocarril y los puertos, a los que dedicará no pocos desvelos y no sólo en el plano teórico $^{100}$.

Desoignie murió en Avilés el 25 de enero de 1898, tras unos últimos años en los que sus facultades - en especial la memoria - fueron per-

96 «Don Adolfo de Soignie», Revista minera, metalúrgica y de ingeniería, n. ${ }^{\circ} 67$, año XLIX, 1898, p. 33. Desoignie, 1867. Carta de Schulz a Desoignie, 23-3-1841, AHAZ, LCC.

${ }_{97}$ L'Indépendance Belge, 2-5-1853, p. 1. De Soignie, 2016, p. 112. Jove y Bravo, 1879 , p. 19.

98 Desoignie, 1850, p. 276.

99 «Fábrica de zinc en Avilés», Revista Minera, T 5, 1854, p. 415.

100 Desoignie, 1850, 1855, 1858, 1863, 1867, 1876, 1877a, 1877b, 1881 y 1882. 
diendo terreno frente a la edad y la enfermedad ${ }^{101}$. Afortunadamente, antes tuvo la iniciativa de escribir la breve historia personal que se ha utilizado con profusión a lo largo de estas páginas. Es en buena medida también la historia de los inicios de la industrialización asturiana.

\section{Fuentes}

Archivo Histórico de Asturiana de Zinc (AHAZ).

ARCHIVo Histórico DE AvilÉs (AHA).

CENTRE LIÈGEOIS D'ARCHIVES ET DE DOCUMENTATION DE L'INDUSTRIE CHARBONNIÈRE (CLADIC).

\section{Bibliografía}

Álvarez FernÁNDEZ, María Violeta, La escuela del paternalismo industrial asturiano 1880-1936, Trea, Gijón, 2006.

ANDUAGA, Aitor, «The engineer as a «linking agent» in international technology transfer: the case of Basque engineers trained in Liège», Engineering Studies, vol. 3, no 1, 2001, pp. 45-70.

ARAGón, Agustín, «Conferencia sobre las aptitudes que deben tener los jóvenes que se dediquen a la carrera de la ingeniería y las dificultades de adquisición de los conocimientos de la misma carrera y ventajas del ejercicio de ésta, dada por el Sr. Ing. Agustín Aragón, el día 26 de Enero de 1906, en la Escuela Nacional Preparatoria», en Anales de la Asociación de Ingenieros y Arquitectos de México, t. X, México, Imprenta y Fototipia de la Secretaría de Fomento, 1906, p. 72, citado por Alejandro GonZÁlEZ MileA, «La ciudad, el campo y el ingeniero de frontera en México (1820-1900)», Boletín de Monumentos Históricos, Tercera Época, n. ${ }^{\circ}$ 35, sept.-dic. 2015, pp. 149-169.

BARAJAS, Óscar Mauricio, «Breve historia de la Ingeniería Mecánica», Ingenierías, 2003, vol. 6, n. ${ }^{\circ} 19$, p. 64.

BRIGODE, J.-F., À propos d'un épisode de la révolution industrielle. Les entreprises Dupont, Bruxelles, s/d.

Coll MarTín, Sebastián y Sudriá I TRIAY, Carles, El carbón en España, 17701961. Una historia económica, Ediciones Turner, Madrid, 1987.

101 «Don Adolfo de Soignie», Revista minera, metalúrgica y de ingeniería, n. ${ }^{\circ} 67$, año XLIX, 1898, p. 33. Bulletin de l'Association des ingénieurs des mines sortis de l'Ecole de Liège, 4-5-1898, p. 64. De Soignie, 2016, p. 129. 
A la cumbre por un valle. Adolphe Desoignie, un ingeniero de minas pionero en la Asturias ...

Deferme, Jo, and MAeYer, Jan de, «Entre sciences sociales et politique. La pensée leplaysienne et les milieux catholiques belges», Les Études Sociales, n. ${ }^{\circ} 149-150,2009$, pp. 147-166.

De la MAdrid, Juan Carlos, Prensa y sociedad en una villa del Cantábrico. Avilés, 1866-1950, Laria, Oviedo, 2008.

De SMAELE, Henk, «Politiek als hanengevecht of cerebraal systeem. Ideeën over politieke representatie en de invoering van de evenredige vertegenwoordiging in België (1899)», BMGN-Low Countries Historical Review, 1999, vol. 114 , n. 3 , pp. 328-357.

De Solgnie, Mercedes, Caminos del ayer, huellas del mañana, HiFer, Avilés, 2016.

Desolgnie, Adolfo, «Descripción, con plano y cortes geognósicos del criadero carbonífero de Arnao», Revista Minera, T1, 1850, p. 276.

Desolgnie, Adolfo, Consideraciones sobre el Proyecto de Ley de Minas sometido a las Cortes Constituyentes por el Excmo. Sr. D. Francisco de Luján en 3 de noviembre de 1854, Imprenta y litografía de Brid, Regadera y C., Oviedo, 1855.

Desolgnie, Adolfo, «Cuenca carbonera de Langreo», Revista Minera, t. IX, 1858, p. 472 .

Desoignie, Adolfo, «Rails de talón y otras mejoras en los ferrocarriles del ingeniero D. Adolfo Desoignie», Revista Minera, T6, 1855, pp. 759-761.

DESOIGNIE, Adolfo, «Cuenca carbonera de Langreo», Revista minera, metalúrgica $y$ de ingeniería, T9, 1858, pp. 472-474.

Desolgnie, Adolfo, «Ferrocarril Asturiano», Gaceta de los caminos de hierro, 117-1863, pp. 6-7, у 2-8-1863, pp. 5-7.

Desoignie, Adolfo, Estudio sobre los puertos de mar, Imp. Pruneda, Avilés, 1867.

Desoignie, Adolfo, «El puerto de Avilés y la industria carbonera de Asturias, Revista minera, metalúrgica y de ingeniería, T27, 1876, pp. 158-161.

Desoignie, Adolfo, Vías férreas. Sustitución de traviesas de madera, Imp. J.M. Lapuente, Madrid, 1877 (a).

Desolgnie, Adolfo, Vías férreas. Nuevo sistema exclusivamente metálico denominado Rail-Placa, Imp. J. M. Lapuente, Madrid, 1877 (b).

Desolgnie, Adolfo, La emigración: sus causas, sus efectos, su fin en Asturias, Imp. Pruneda, Avilés, 1881.

Desolgnie, Adolfo, Apuntes sobre el gran puerto asturiano, Imp. Pruneda, Avilés, 1882.

Desoignie, Adolfo, «Apuntes biográficos. Diciembre 1884», en Mercedes De SoIGnie, Caminos del ayer, huellas del mañana, HiFer, Avilés, 2016.

EZQUERRA DEL BAYO, Joaquín, Elementos de laboreo de minas, precedidos de algunas nociones sobre geognosia y la descripción de varios criaderos de minerales, tanto de España como de otros reinos de Europa, Imp. Vda. de Yenes, Madrid, 1839. 
EzQuerra, Joaquín et al., Minas de carbón de piedra de Asturias. Reconocimiento hecho de orden del Rey nuestro señor por una comisión de facultativos, Imprenta de Don José del Collado, Madrid, 1831.

FERrEIRO, Larrie D., «Goodall in America: The Exchange Engineer as Vector in International Technology Transfer», Comparative Technology Transfer and Society, 2006, vol. 4, n. ${ }^{\circ}$, pp. 172-193.

García LóPEZ, José Ramón, PERIBAÑEz, Daniel y DARocA, Alejandro, Asturiana de Zinc: una historia a través de tres siglos, Asturiana de Zinc, Madrid, 2004.

GARÇON, Anne-Françoise, Entre l'état et l'Usine. L'École des mines de SaintÉtienne au XIXe siècle, Presses Universitaires de Rennes, Rennes, 2004.

GonzÁlez LaSAla, José, Memoria sobre las minas de carbón de piedra de Arnao (Asturias, 1847). Introducción y notas: José Sierra Álvarez, Centro de Estudios Rurales de Cantabria, Cantabria, 1991.

GonZÁLEZ Llanos, Rafael, «Proyectos industriales del Exmo. Sr. Marqués de las Marismas», El Nalón, n. ${ }^{\circ}$ 8, 8-5-1842.

GonZÁlez Prieto, Luis Aurelio, Oro negro, dinero sucio. Una nueva historia de la minería asturiana, Laria, Oviedo, 2017.

González-Pumariega Solís, Pelayo, y GonzÁlez Prieto, Luis Aurelio, «Guillermo Schulz (1805-1877) y la Société Géologique de France», Boletín Geológico y Minero, 128 (1), 2017, pp. 221-240.

Jove y Bravo, Rogelio, Guía civil, eclesiástica y militar de la provincia de Asturias, 1878-1879, Impr. de Vallina y Compañía, Oviedo, 1879.

Llaneza Díaz, Jesús, y Trinidad, Francisco, ... Y se hizo la luz. Evolución tecnológica de las lámparas de mina, Fundación Emilio Barbón, Gijón, 2009.

Mansilla PlazA, Luis, "Aproximación a la evolución de la tecnología minera a lo largo del siglo XIX», Cuadernos de Estudios Manchegos, n. . 36, 2011, pp. 93-109.

MuÑIz Prada, Nicanor, Apuntes para la topografía médica del concejo de Mieres y su comarca minera, Oviedo, 1885.

MuÑIZ SÁNCHEZ, Jorge, «El germen belga de la industrialización en el Norte de España. Asturias, 1833-1838», Signos Históricos, n. . 41, 2019, pp. 42-67. En línea: https://signoshistoricos.izt.uam.mx/index.php/historicos/article/ view/547/507

MuÑIz SÁncheZ, Jorge, Del pozo a casa. Genealogías del paternalismo minero contemporáneo en Asturias, Trea, Gijón, 2007.

NADAL, Jordi, El fracaso de la revolución industrial en España, 1814-1913, Ariel, Barcelona, 1975.

Pasleau, Suzy, «Les innovations techniques dans les mines de charbon (fin XVIIIe-milieu XIXe siècles. Les échanges entre les bassins de Liège, d'Aixla-Chapelle et de la Ruhr: facteurs d'expansion», in A.M. van der Woude (coord.), Rélations économiques dans les régions frontalières à l'ère industrielle, 1750-1965, Eisma B.V., Leeuwarden, 1996, pp. 140-144. 
A la cumbre por un valle. Adolphe Desoignie, un ingeniero de minas pionero en la Asturias ...

PoRto, Juan do, Reseña histórica de los últimos acontecimientos políticos de Galicia, Imprenta de la Viuda de Burgos, Madrid, 1846.

ScHulz, Guillermo, «Concluye el informe sobre algunas minas de carbón de Asturias», Boletín Oficial de Minas, 1844, pp. 141-143.

SHUBERT, Adrian, Hacia la revolución. Orígenes sociales del movimiento obrero en Asturias, Crítica, Barcelona, 1984.

SIERRA Álvarez, José, «Introducción», en José GonZÁlez LASAlA: Memoria sobre las minas de carbón de piedra de Arnao (Asturias, 1847). Introducción y notas: José Sierra Álvarez, Centro de Estudios Rurales de Cantabria, Cantabria, 1991, pp. 3-7.

SiERra Álvarez, José, El obrero soñado. Ensayo sobre el paternalismo industrial (Asturias, 1860-1917), Siglo XXI, Madrid, 1990.

Vilela CAMPO, Alberto, Avilés: carbón y veleros, Alberto Vilela, Avilés, 2008.

\section{Datos del autor}

Jorge Muñiz (Oviedo, 1978) es profesor de la Universidad de Oviedo y sus líneas de investigación principales giran en torno a la historia social de la minería. El interés por la historia comparada le ha llevado a desarrollar estancias en las universidades de Tours y Paris 1 Panthéon-Sorbonne que le permitieron obtener el Doctorado Europeo y posteriormente investigar sobre las minas del Norte de Francia gracias a un contrato postdoctoral del Plan de I+D+I del Principado de Asturias. 